\title{
APPLICATION OF SEMICONDUCTOR DETECTOR FOR RECORDING THE RAYLEIGH SCATTERING OF MÖSSBAUER RADIATION
}

\author{
J. Reklaitis, D. Baltrūnas, V. Remeikis, and K. Mažeika \\ State Research Institute Center for Physical Sciences and Technology, Savanoriu 231, LT-02300 Vilnius, Lithuania \\ E-mail: dalis@ar.fi.lt
}

Received 8 October 2010; revised 23 November 2010; accepted 15 December 2010

\begin{abstract}
The method of the Rayleigh scattering of Mössbauer radiation (RSMR) for the study of dynamics of atoms in polystyrene demonstrating advantages of the application of the semiconductor Si-PIN detector (Amptek Inc.) was used for recording scattered radiation. It has been shown that for recording the RSMR spectra the semiconductor detector can be much more suitable than other types of detection because of the increased quality of spectra under the same collimating conditions. The dependence of probability of the Rayleigh elastic scattering $f_{R}$ on the scattering angle was obtained. By means of the RSMR method the scattering was studied within the angle range at the main Bragg maximum of a polystyrene sample which corresponds to the distance $d=4.44 \AA$ approximately equal to the distance between the polymer chains.
\end{abstract}

Keywords: Mössbauer spectroscopy, Rayleigh scattering, detector, dynamics of atoms

PACS: $76.80 .+\mathrm{y} ; 29.40 .-\mathrm{n}$

\section{Introduction}

The attention to the investigation of dynamics of atoms, and especially collective dynamics of biomolecules and proteins, increased very much because of the importance of their biological functions [1-3]. Such informative methods as X-ray dynamical analysis, nuclear magnetic resonance, neutron scattering are used for these investigations [4]. The additional method which could be used for these purposes is Mössbauer spectroscopy, which is distinguished for the grand resolving power.

However, the traditional Mössbauer spectroscopy has one essential drawback - the material under investigation should contain (as the main component or as impurity) identical Mössbauer nuclei as in the source. Thus, the traditional Mössbauer spectroscopy is difficult to apply for the investigation of the dynamics of biomolecules and proteins. As a result, a new method based on the same Mössbauer effect but not requiring Mössbauer isotopes to be in the samples, the Rayleigh scattering of Mössbauer radiation (RSMR), has been developed and used [5-10]. In this method, the Mössbauer gamma-radiation is scattered by the electron cloud of atoms of the investigated materials. The part of elastic scattered gamma-quanta $\left(f_{\mathrm{R}}\right)$ or the spectrum shape are analysed by the absorber containing Mössbauer nuclei. In principle, RSMR is the same X-ray diffraction, only instead of the $\mathrm{X}$-ray source the radioactive gamma-source is used (for ${ }^{57} \mathrm{Co}$ source wavelength of radiation $\lambda=0.86 \AA$ ). The main advantage as compared with the $\mathrm{X}$-ray diffraction method is the resolving power which is much higher. Thus, using the Rayleigh scattering of Mössbauer radiation it is possible to investigate materials which do not contain Mössbauer isotopes. The RSMR method can be used in such cases because it is capable of detecting variations in the energy of the diffracted photons comparable with the typical width of the Mössbauer line $\left(\sim 10^{-9} \mathrm{eV}\right.$ for $\left.{ }^{57} \mathrm{Fe}\right)$ [9]. Such high energy resolution allows the experimental separation of elastic and inelastic scattering [11].

As mentioned earlier, in most researches, including our investigations [12-16], the conventional Mössbauer spectroscopy and related methods (calibration of the isomer shifts [17]) are prevailing, however, the recent publications show that the interest in RSMR increases [18-21]. 


\section{Application possibilities of the RSMR method}

One of the first papers demonstrating that the RSMR method "works" was published in 1960 [11]. Its authors investigated scattering at a large angle $\left(50^{\circ} \pm 5^{\circ}\right)$ from different materials (platinum, aluminum, graphite, and paraffin) using a tin source. The amount of elastically scattered photons well coincided with the theoretically calculated value. The authors also used a thin ${ }^{119} \mathrm{Sn}$ foil as a scatterer and observed a resonant Mössbauer scattering (source ${ }^{119} \mathrm{Sn}$, scatterer ${ }^{119} \mathrm{Sn}$ ).

According to [9], for the RSMR method the characteristic time $\tau_{\mathrm{c}} \sim 1 / \Gamma$ depends on the natural width of the Mössbauer line $\Gamma$. It defines the time scale on which dynamic processes can be analysed using the RSMR method. After analysis of the boundary conditions the authors showed that elastic scattering was impossible in the solid amorphous polymer systems and liquids with low viscosity, when diffusion processes for which relationship $\tau_{\mathrm{r}} \ll \tau_{\mathrm{c}}$ is valid ( $\tau_{\mathrm{r}}$ is relaxation time) prevailed. This conclusion was confirmed experimentally when the dependence of the amount of scattered quanta on the angle of scattering was investigated.

Singwi and Sjolander [22] adapted the neutron scattering theory to gamma rays and proposed to analyse diffusion in solids or in viscous liquids taking into account broadening of the Mössbauer line. They drew the conclusion that the line broadening in solids depended on the observation angle of diffusion.

$\mathrm{BaTiO}_{3}$ and $\mathrm{Ba}_{0.54} \mathrm{Sr}_{0.46} \mathrm{Nb}_{2} \mathrm{O}_{6}$ monocrystals in the vicinity of the phase transition were investigated using the Rayleigh scattering of Mössbauer radiation in [23]. A large (6-7 $\Gamma)$ broadening of the Mössbauer line showed that during the phase transition slow processes dominated with the characteristic frequency equal to 5-10 MHz. Results are in a qualitative agreement with the hypothesis that paraelectric and ferroelectric phases of $\mathrm{Ba}_{0.54} \mathrm{Sr}_{0.46} \mathrm{Nb}_{2} \mathrm{O}_{6}$ are considered as quantum mechanical states separated by a low barrier of $\sim 0.4 \mathrm{eV}$, between which fluctuating transition can occur.

Later [6] the same $\mathrm{BaTiO}_{3}$ monocrystal was investigated and authors did not observe any broadening of the line in the vicinity of the phase transition which could be explained as the existence of the low frequency $(\sim 10 \mathrm{MHz})$ excitations. Thus, this article denied the results obtained in the analogous work [23].

The RSMR method for studying the dynamics of atoms in a condensed phase was reviewed in the work [5].

The dependence of the scattering intensity on both the scattering vector $\left(0.2\right.$ to $\left.9.4 \AA^{-1}\right)$ and temperature (at room temperature and after heating to $145^{\circ} \mathrm{C}$ ) in the L-Dopa melanine has been investigated [10]. Analogous measurements were also performed by X-ray diffraction. As the speed of spectra registration was much higher in the latter case, it was possible to distinguish fine structure of the spectra. From the measurement data the radial distribution function was calculated. Its maxima coincided with typical lengths of chemical bonds of the monomer (1.45 and $2.4 \AA$ ). When temperature was increased, all maxima moved towards longer lengths and it was explained by the thermal expansion. The authors noticed that some maxima disappeared. It was explained by the increase in the mobility of the water molecules in the vicinity of melanine. The polymer system under investigation is distinguished for high anisotropy. After evaluation of the mean square displacement it became evident that mean square displacements which coincided with the monomer plane were several times smaller than those in the perpendicular direction.

The angular dependences of inelastic intensities of the Rayleigh scattering of Mössbauer radiation for lysozyme and myoglobin at different degrees of hydration were investigated as well [24, 25]. The study of the radial distribution function deduced by Fouriertransform from the diffuse X-ray measurements together with RSMR data showed that the water during hydration of proteins competed with the intramolecular hydrogen bonds and increased the internal dynamics. Krupyanskii et al. published a critical review of protein dynamics studies by the RSMR method and evaluated the influence of coherence effects [4].

The dynamics of atoms of the sample is very often expressed through the autocorrelation function. This function can be expressed in terms of the absorption or emission spectra (spectral function $g(\omega)$ ). Usually, the autocorrelation function is calculated by the numerical methods from the Mössbauer spectra, but the function obtained in such a case significantly depends on the primary dynamical model [26]. The method of determination of the autocorrelation function directly calculating Fourier-transform of the Mössbauer spectra was proposed. This method allows one to analyse even those spectra, the form of which cannot be described by the Lorentz components (non-Lorentzian). The authors have also shown that it is possible to divide the autocorrelation function into three independent components: high frequency motions (with frequencies $\omega \gg \Gamma$ ), local vibrations (with frequencies $\omega \leq \Gamma$ ), and quasidiffusion. Such analysis was applied to the inves- 
tigation of the human protein serum in the temperature range of $270-310 \mathrm{~K}$.

Based on this model [26], the authors of [27] compared data obtained by the Mössbauer and X-ray spectroscopy. The main attention was paid to the dependence of the mean square displacements $\left\langle x^{2}\right\rangle$ on temperature. According to the Mössbauer data, the intensity of the absorption lines drops when the critical temperature $T_{\mathrm{c}}$ is exceeded and absorption lines broaden. An interpretation of such behaviour of the system was proposed by the authors and some discrepancies between Mössbauer and X-ray data were also explained. According to this explanation, X-ray structural analysis evaluates the protein in different conformational states (a static process), while the Mössbauer spectroscopy allows investigating the protein in the intermediate state, among different conformational states (a dynamical process).

A large-diameter proportional detector (active area $700 \times 700 \mathrm{~mm}^{2}$ ) suitable for RSMR and X-ray diffraction experiments was described in [28]. The detector can detect many reflexes at the same time and it allows reducing the measurement time more than 100 times. The active zone of the detector is divided into $1024 \times 1024$ separate channels (points). The construction of the detector, the composition of the gas mixture, and working modes are described in detail. Dynamics of myoglobin using this detector has been investigated [29]. Both crystalline and dry myoglobin was investigated over a wide range of angles $\left(9^{\circ} \leq 2 \theta \leq\right.$ $19^{\circ}$ ). For the detection of scattered emission, the multiwire proportional detector was used [28]. These experiments corroborated with results of other analogous investigations - they showed that water had a large influence on the mobility of the protein. A motion of large fragments (from 4 to $10 \AA$ ) dominated in the crystalline myoglobin (possessing the crystallographic water). In the dry myoglobin the mean square displacement $\left\langle x^{2}\right\rangle$ is approximately 5 times smaller than in the crystalline one (0.06 and $0.27 \AA$, accordingly). Vibrations analogous to those in solids prevail in the dry myoglobin, vibrations characteristic of the protein disappear.

Using the same multichannel proportional counter, Zach et al. also investigated dynamics of myoglobin [30]. It is interesting to note that the authors used not only the ordinary ${ }^{57} \mathrm{Fe}$ source but also ${ }^{183} \mathrm{~W}$ [28]. Using these two sources the authors [30] measured the angular dependence from $\sin (\theta) / \lambda=0.04 \AA^{-1}$ to $\sin (\theta) / \lambda=$ $0.44 \AA^{-1}$. The measured value of $f_{\mathrm{R}}$ coincided for both sources. This fact shows that measured dynamics is dominated by motions faster than $0.2 \mathrm{~ns}$.
A different method of investigations of myoglobin and other proteins possessing heme-groups was applied in [31]. The dynamics and electronic structure of the heme-group were investigated by conventional Mössbauer spectroscopy because this group contains $\mathrm{Fe}$ atoms, while other materials were investigated by the RSMR method. It was shown that conformational movements in the heme-group could be investigated both by RSMR and conventional Mössbauer spectroscopy methods if their frequency is higher than $10^{7} \mathrm{~s}^{-1}$, and that the processes with low frequency could be investigated analysing electronic states of $\mathrm{Fe}$ atoms in the heme-group.

\section{Theoretical basis}

General theory of the Rayleigh scattering is essentially the same as that of conventional X-ray scattering [31, 32]. The scattering differential cross-section is

$$
J(k)=N|F(k)|^{2} S(k),
$$

where $N$ is the number of atoms in the crystal, $F(k)$ is the atomic form factor, $S(k, \omega)$ is the scattering function, which describes dynamic properties of the scatterer. $S(k, \omega)$ is difficult to measure, and one usually obtains the total integrated function instead of $S(k)$. If one accepts harmonic approximation, $S(k)$ can be expanded as

$$
S(k)=S_{0}(k)+S_{1}(k)+S_{2}(k)+\cdots,
$$

where the first term corresponds to elastic scattering $\left(S_{0}(k)=S_{\mathrm{el}}(k)\right)$, while other terms describe inelastic scattering by one or more phonons. The gamma photon energy change is usually less than $10^{-3} \mathrm{eV}$. The energy resolution of ordinary $\mathrm{X}$-ray spectroscopy is very poor, not sufficient to separate elastic scattering from inelastic one, both of which contribute to the same Bragg peak. But these two components can be separated using the RSMR method.

There are several experimental methods to separate elastic and inelastic scattering. We have used four measurement techniques [32]. The absorber is placed between the scatterer and the detector (Fig. 1, $\mathrm{A}_{\mathrm{det}}$ position), the source velocity is adjusted so that no resonance takes place, and the photon count is expressed as

$$
I_{\infty}(\theta)=I(0) P \mathrm{e}^{-\mu_{\mathrm{a}} d}+I_{\mathrm{b}},
$$

where $\mu_{\mathrm{a}}$ is the atomic mass absorption coefficient, $d$ is the thickness of the analyzer, $I_{\mathrm{b}}$ is the background count, $I(0)$ is the total number of photons from the 


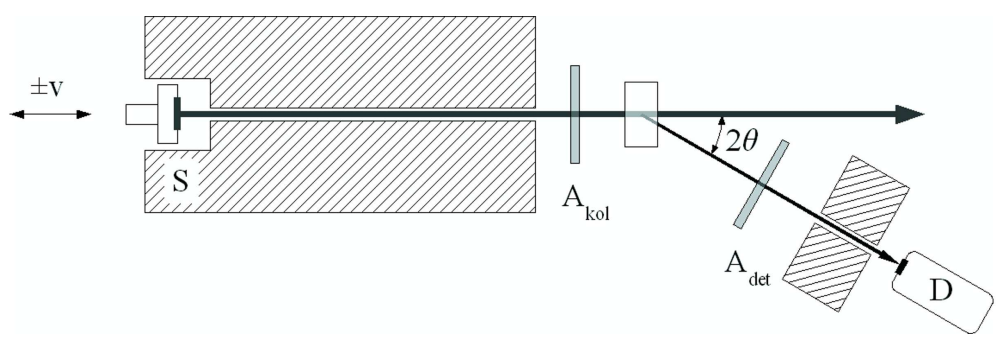

Fig. 1. A sketch of spectrometer ( $S$ is source, $D$ is detector, $A_{k o l}$ and $A_{\text {det }}$ are positions of the analyzer, $\pm v$ is velocity of the source regarding the absorber).

source, and $P$ is the total scattering probability of incident gamma rays being scattered in the $\theta$ direction. The second measurement is made when the source velocity is adjusted to resonance energy, and the photon count is

$$
\begin{aligned}
I_{\mathrm{r}}(\theta)= & I(0) f_{\mathrm{s}} P_{\mathrm{el}} \mathrm{e}^{-\left(\mu_{\mathrm{a}}+\mu_{\mathrm{r}}\right) d}+I(0) f_{\mathrm{s}} P_{\mathrm{in}} \mathrm{e}^{-\mu_{\mathrm{a}} d} \\
& +I(0)\left(1-f_{\mathrm{s}}\right) P \mathrm{e}^{-\mu_{\mathrm{a}} d}+I_{\mathrm{b}}
\end{aligned}
$$

The first term corresponds to the intensity of elastic scattering, the second to inelastic one, the third term is the scattered intensity of non-recoilless radiation $\left(\mu_{\mathrm{r}}\right.$ is the resonance absorption coefficient, $P_{\mathrm{el}}, P_{\mathrm{in}}$ are the probabilities of incident gamma rays being scattered elastically or inelastically in the $\theta$ direction, and $f_{\mathrm{s}}$ is a recoilless fraction in the source). Corresponding measurements are made when the absorber is placed between the source and the scatterer (Fig. 1, $\mathrm{A}_{\mathrm{kol}}$ position). The third measurement:

$$
I_{\infty}^{\prime}(\theta)=I(0) P \mathrm{e}^{-\mu_{\mathrm{a}} d}+I_{\mathrm{b}}^{\prime},
$$

and the fourth measurement:

$$
\begin{aligned}
I_{\mathrm{r}}^{\prime}(\theta)= & I(0) f_{\mathrm{s}} P \mathrm{e}^{-\left(\mu_{\mathrm{a}}+\mu_{\mathrm{r}}\right) d} \\
& +I(0)\left(1-f_{\mathrm{s}}\right) P \mathrm{e}^{-\mu_{\mathrm{a}} d}+I_{\mathrm{b}}^{\prime} .
\end{aligned}
$$

Difference of the intensity is expressed as

$$
\begin{gathered}
\Delta I=I_{\infty}-I_{\mathrm{r}}=I(0) P_{\mathrm{el}} f_{\mathrm{s}} \mathrm{e}^{-\mu_{\mathrm{a}} d}\left(1-\mathrm{e}^{-\mu_{\mathrm{r}} d}\right), \\
\Delta I^{\prime}=I_{\infty}^{\prime}-I_{\mathrm{r}}^{\prime}=I(0) P f_{\mathrm{s}} \mathrm{e}^{-\mu_{\mathrm{a}} d}\left(1-\mathrm{e}^{-\mu_{\mathrm{r}} d}\right) .
\end{gathered}
$$

Therefore, RSMR probability of elastic scattering $f_{\mathrm{R}}$ can be expressed as

$$
f_{\mathrm{R}}=P_{\mathrm{el}} / P=\Delta I / \Delta I^{\prime} .
$$

It can be clearly seen that this method eliminates the need to measure the background intensity, there is no need to evaluate parameters $\mu_{\mathrm{a}}, \mu_{\mathrm{r}}, f_{\mathrm{s}}$, and $I(0)$ and thus separation of elastic and inelastic scattering can be accomplished more precisely.

\section{Experimental technique}

The standard Mössbauer spectrometer by Wissel (Wissenschaftliche Elektronik $\mathrm{GmbH}$ ) was upgraded to fit RSMR measurements by adding a goniometer and beam collimators.

The main beam is collimated with the lead collimator, the length of which is $200 \mathrm{~mm}$. This collimator gives a constant beam divergence equal to $1^{\circ}$. The scattered beam is collimated with the second collimator. By changing the distance between the detector and the scatterer one can change the beam divergence from $1^{\circ}$ to $5^{\circ}$.

The goniometer allows us to change the scattering angle $2 \theta$ from $0^{\circ}$ to $55^{\circ}$, with the accuracy of $3 \mathrm{~min}$. Measurements were done at room temperature using the source of ${ }^{57} \mathrm{Co}$ in $\mathrm{Rh}$ matrix. Scattered radiation was analysed with the "black" analyzer (ammonium lithium fluorferrate). Mössbauer radiation was scattered with the polystyrene cylinder.

\section{Results}

In this work we present our experimental results obtained using two different types of detectors - the proportional gas counter (Wissenschaftliche Elektronik $\mathrm{GmbH}$ ) and the semiconductor Si-PIN detector manufactured by Amptek Inc.

In ${ }^{57} \mathrm{Co}$ energy spectra, recorded with the proportional gas counter (Fig. 2, A), one can easily recognize the iron $\mathrm{K}$ line, the Mössbauer line, and Rh fluorescence. The iron $\mathrm{K}$ line has reduced intensity because the Al filter was used on the detector window. The same spectra recorded with the semiconductor detector give a much better energy resolution (Fig. 2, B). It was possible to determine structure of $\mathrm{X}$-ray energy spectra: iron $\mathrm{K}$ series $\left(\mathrm{K}_{\alpha} 6.40 \mathrm{keV}\right.$ and $\left.\mathrm{K}_{\beta} 7.04 \mathrm{keV}\right)$ and lead $\mathrm{L}$ series $\left(\mathrm{L}_{\alpha} 10.5 \mathrm{keV}\right.$ and $\left.\mathrm{L}_{\beta} 12.6 \mathrm{keV}\right)$.

We also evaluated the Mössbauer linewidth for both spectra (Fig. 2). For the proportional gas counter the full width at half maximum (FWHM) is $1.3 \mathrm{keV}$, and for the semiconductor detector FWHM is $0.3 \mathrm{keV}$. 


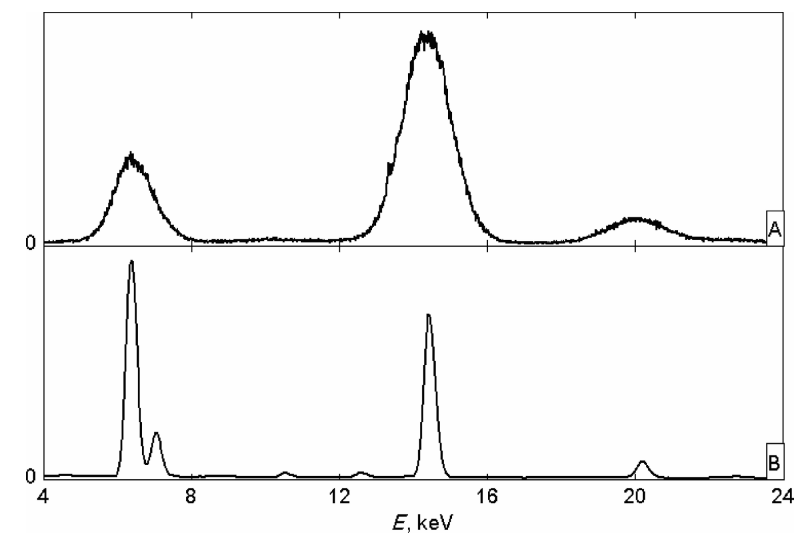

Fig. 2. ${ }^{57} \mathrm{Co}(\mathrm{Rh})$ amplitude spectrum: $A$ for proportional gas counter, $B$ for semiconductor detector.

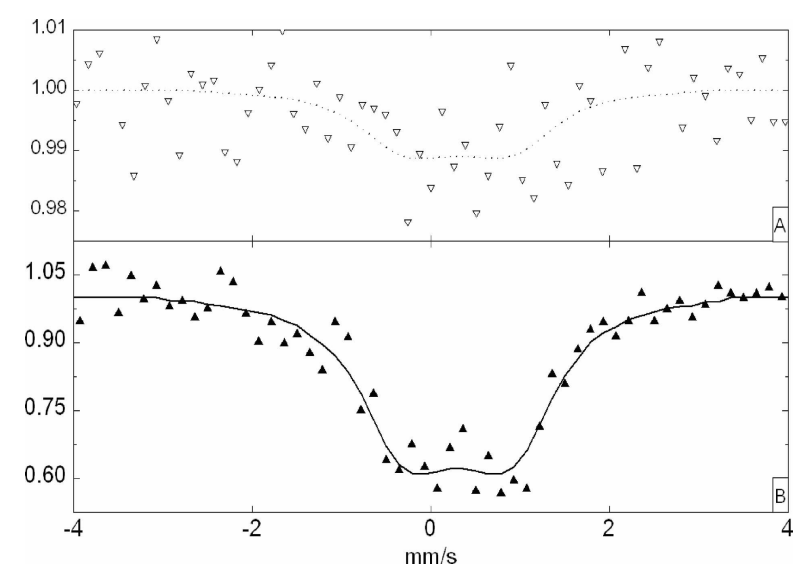

Fig. 3. RSMR spectrum of black absorber when $2 \theta=6^{\circ}$.

For simplicity a conventional Mössbauer spectrum of the black absorber was fitted to sextet (hyperfine magnetic interaction with low field $\sim 3 \mathrm{~T}$ ). Other fitting parameters (the isomer shift, quadrupole splitting, linewidth) were fixed and used for fitting RSMR spectra.

The spectrum obtained using a proportional gas counter is shown in Fig. 3, A. The measurements lasted about a week, but statistics was poor and the observed effect was very small $\left(f_{\mathrm{R}} \sim 1 \%\right)$. When the detector was changed to the semiconductor detector, the qualitative leap was obtained: the measurement time shortened to two days and the value of the effect increased to $40 \%$ (Fig. 3, B). In both cases the geometry of the experiment and the sample was the same.

It is known that $\mathrm{K}_{2} \mathrm{MgFe}(\mathrm{CN})_{6}$ is distinguished for the narrow single line and a small isomer shift, and it was used in our experiments as an analyzer by investigating the dependence of the RSMR probability on the scattering angle. The latter was changed every two degrees. At each angle two spectra were registered by

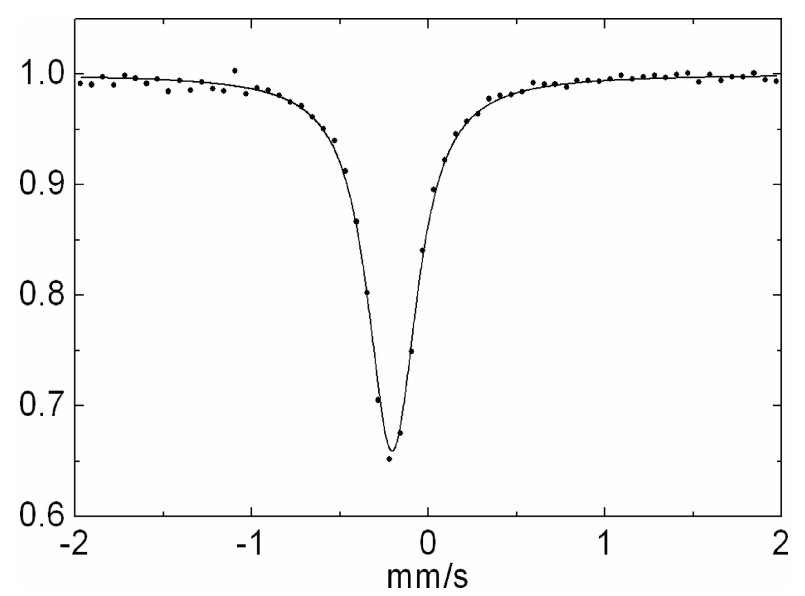

Fig. 4. Typical Mössbauer spectrum of $\mathrm{K}_{2} \mathrm{MgFe}(\mathrm{CN})_{6}$ when $2 \theta=$ $0^{\circ}$.

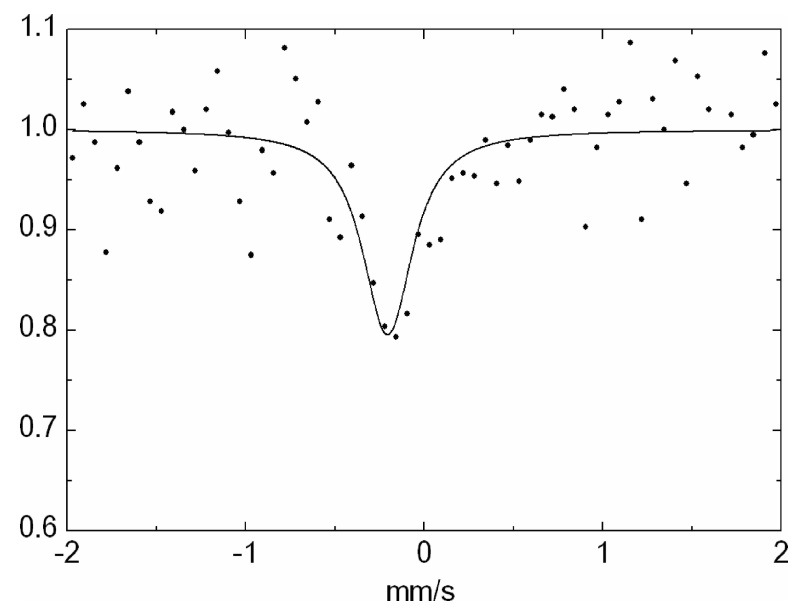

Fig. 5. Typical spectrum of $\mathrm{K}_{2} \mathrm{MgFe}(\mathrm{CN})_{6}$ when $2 \theta=9^{\circ}$ and analyzer is in $A_{\text {det }}$ position (see Fig. 1).

changing the position of the analyzer (Fig. 1, $\mathrm{A}_{\mathrm{kol}}$ and $\left.A_{\text {det }}\right)$.

The measured spectrum with good statistics (more than 50000 counts per channel, Fig. 4) was fitted to Lorentzian $(\delta=-0.204 \pm 0.001 \mathrm{~mm} / \mathrm{s}, \Gamma=0.313$ $\pm 0.004 \mathrm{~mm} / \mathrm{s}$ ) and these parameters were used later for fitting spectra with the poorer statistics (100 counts per channel, Fig. 5).

It is known that the peak area is proportional to the intensity of the elastic scattering, thus the ratio of the peak areas according to Eq. (9) is equal to the probability of the elastic Rayleigh scattering $f_{\mathrm{R}}$. Dependence of $f_{\mathrm{R}}$ on the scattering angle is shown in Fig. 6 .

For the comparison the same sample of polystyrene was analysed using X-ray diffraction (XRD). XRD pattern (Fig. 7) was recorded in $0.04^{\circ}$ steps. It has two maxima, at $19.96^{\circ}$ and at $23.80^{\circ}$, which corresponds to the distance between planes, 4.45 and $2.07 \AA$, respectively. In order to compare different types of 


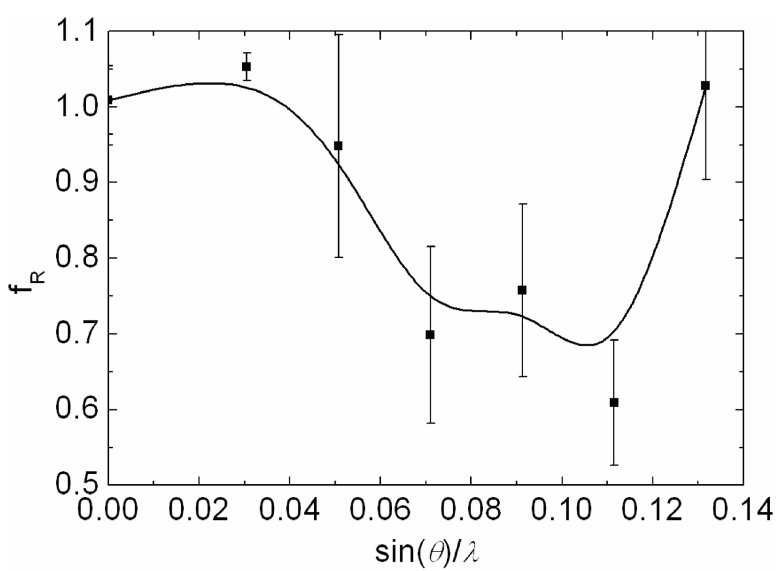

Fig. 6. Dependence of $f_{\mathrm{R}}$ on the scattering vector $\sin (\theta) / \lambda$.

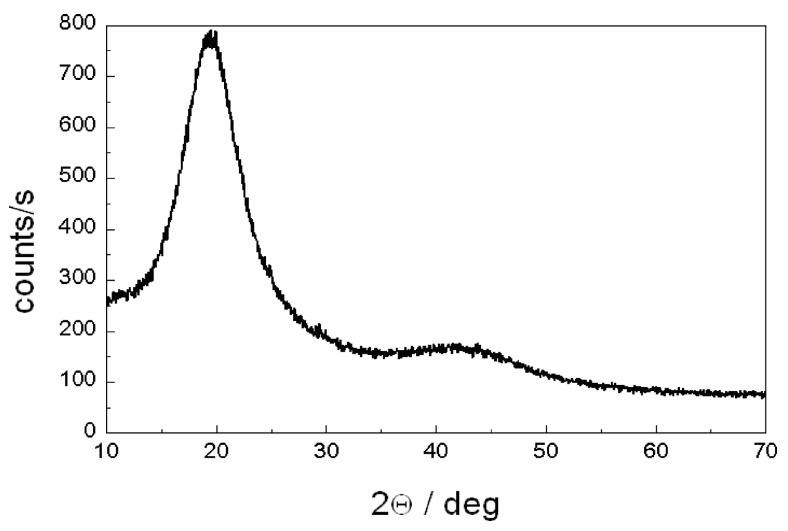

Fig. 7. XRD pattern of polystyrene.

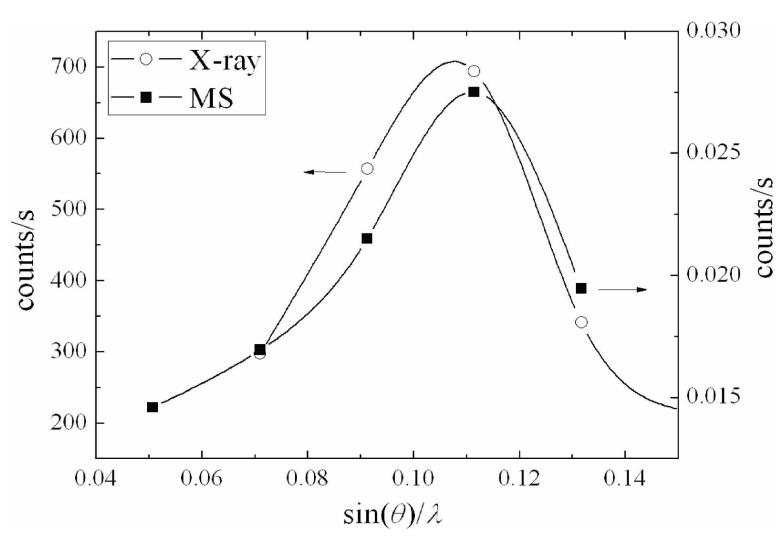

Fig. 8. Dependence of averaged X-ray and Mössbauer radiation intensities on the scattering vector $\sin (\theta) / \lambda$.

measurements, the intensity of XRD was averaged over the angular step, which was used in RSMR measurements (Fig. 8). The Mössbauer radiation intensity was multiplied by elastic scattering probability in order to separate elastic scattering from inelastic one (Fig. 9).

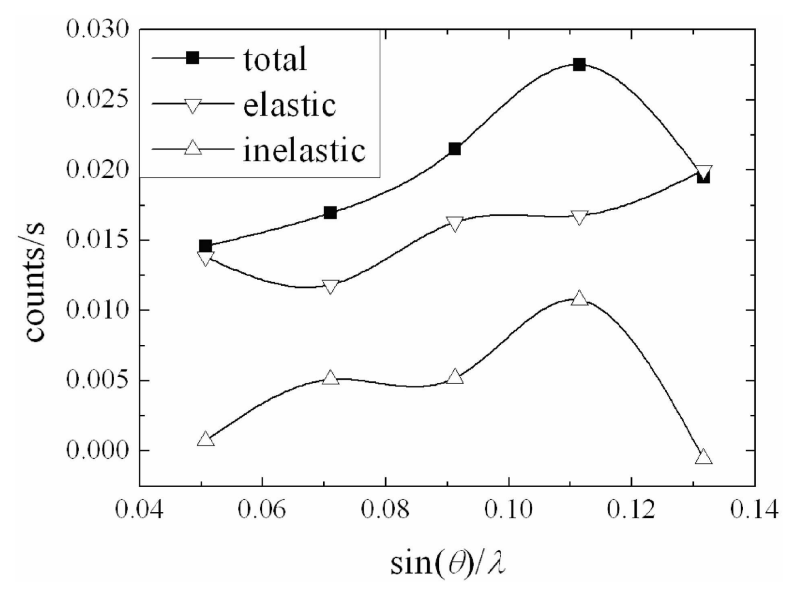

Fig. 9. Dependence of intensities of the Mössbauer radiation on the scattering vector $\sin (\theta) / \lambda$.

\section{Conclusions}

As far as it is known the Rayleigh scattering of Mössbauer radiation can be one of the best methods suitable for the investigation of the dynamics of atoms, e. g. in the vicinity of the phase transition and for the studies of complicated dynamics of biomolecules. However, RSMR experiments are limited mainly because of low intensity of scattered radiation of the Mössbauer source. Our study applying the semiconductor Si-PIN detector (Amptek Inc.) for the investigation of dynamics of atoms in polystyrene has shown that for recording the RSMR spectra the semiconductor detector can be much more suitable than other types of detection because of the increased quality of spectra under the same collimating conditions.

The dependence of probability of the Rayleigh elastic scattering $f_{\mathrm{R}}$ on the scattering angle was obtained. By means of the RSMR method the scattering was studied over the angle range at the main Bragg maximum of the polystyrene sample which corresponds to the distance $d=4.44 \AA$ approximately equal to the distance between the polymer chains.

\section{Acknowledgement}

The authors express their appreciation to Dr. R. Juškènas (State Research Institute Center for Physical Sciences and Technology, Vilnius) for X-ray measurements.

\section{References}

[1] F.G. Parak, Physical aspects of protein dynamics, Rep. Prog. Phys. 66, 103 (2003). 
[2] J.W. Taraska, M.C. Puljung, N.B. Olivier, G.E. Flynn, and W.N. Zagotta, Mapping the structure and conformational movements of proteins with transition metal ion FRET, Nature Methods 6, 532 (2009).

[3] L. Valkunas, J. Janusonis, D. Rutkauskas, and R. van Grondelle, Protein dynamics revealed in the excitonic spectra of single LH2 complexes, J. Luminesc. 127, 269-275 (2007).

[4] Yu.F. Krupyanskii, V.I. Goldanskii, G.U. Nienhaus, and F.G. Parak, Dynamics of protein-water systems revealed by Rayleigh scattering of Moessbauer radiation. Hyperfine Interact. 53, 59-74 (1990).

[5] D.C. Champeney, The scattering of Mössbauer radiation by condensed matter, Rep. Prog. Phys. 42, 10171053 (1979).

[6] C.N.W. Darlington and D.A. O'Connor, On the crystal dynamics of $\mathrm{BaTiO}_{3}$ near $T_{\mathrm{c}}$, Phys. Status Solidi A 96, 509 (1986).

[7] V.I. Goldanskii and Yu.F. Krupyanskii, Protein and protein-bound water dynamics studied by RSMR, Quart. Rev. Biophys. 22, 39-92 (1989).

[8] Yu.F. Krupyanskii and V.I. Goldanskii, RSMR comparison of dynamic properties of various proteins, in: Protein Folding, Evolution and Design, Proceedings of the International School of Physics "Enrico Fermi" Course CXLV, eds. R.A. Broglia and I. Shakhnovich (IOS Press, Amsterdam, 2001) pp. 25-37.

[9] G. Albanese and A. Deriu, Influance of low frequency excitations of the Rayleigh scattering of Mössbauer radiation, Phys. Status Solidi B 107, K115 (1981).

[10] G. Albanese, M.G. Bridelli, and A. Deriu, Structural dynamics of melanin investigated by Rayleigh scattering of Mössbauer radiation, Biopolymers 23, 1481 (1984).

[11] C. Tzara and R. Barloutaud, Recoiless Rayleigh scattering in solids, Phys. Rev. Lett. 4, 405 (1960).

[12] A. Jagminas, R. Ragalevičius, K. Mažeika, J. Reklaitis, V. Jasulaitienė, A. Selskis, and D. Baltrūnas, A new strategy for fabrication $\mathrm{Fe}_{2} \mathrm{O}_{3} / \mathrm{SiO}_{2}$ composite coatings on the Ti substrate, J. Solid State Electrochem. 14, 271 (2010).

[13] A. Jagminas, K. Mažeika, E. Juška, J. Reklaitis, and D. Baltrūnas, Electrochemical fabrication and characterization of lepidocrocite $(\gamma-\mathrm{FeOOH})$ nanowire arrays, Appl. Surf. Sci. 256, 3993-3996 (2010).

[14] A. Jagminas, K. Mažeika, J. Reklaitis, M. Kurtinaitiene, and D. Baltrunas, Template synthesis, characterization and transformations of iron nanowires while aging, Mater. Chem. Phys. 109, 82-86 (2008).

[15] A. Amulevicius, D. Baltrunas, V. Bendikiene, A. Daugvila, R. Davidonis, and K. Mazeika, Investigation of the magnetic properties of nanocrystalline $\mathrm{Fe}_{3} \mathrm{O}_{4}$ precipitated on the surface of chitin, Phys. Status Solidi A 189, 243-252 (2002).

[16] Yu.M. Vysochanskii, D. Baltrunas, A.A. Grabar, K. Mazeika, K. Fedyo, and A. Sudavicius, ${ }^{119} \mathrm{Sn}$ and
XPS spectroscopy of $\mathrm{Sn}_{2} \mathrm{P}_{2} \mathrm{~S}_{6}$ and $\mathrm{SnP}_{2} \mathrm{~S}_{6}$ crystals, Phys. Status Solidi B 246, 1110-1117 (2009).

[17] V.V. Remeikis, A.K. Dragunas, K.V. Makariunas, and B.P. Ruziale, Change of the electron-capture probability-positron Ga-68 decay probability ratio in chemical compounds, Izv. Akad. Nauk SSSR Ser. Phys. 52, 2-4 (1988) [in Russian].

[18] S.E. Enescu and I. Bibicu, Rayleigh scattering of Mössbauer radiation method used in dynamics studies of condensed matter, Acta Phys. Pol. A 107, 479 (2005).

[19] A. Deriu, F. Cavatorta, and G. Albanese, Rayleigh scattering of Mössbauer radiation in hydrated amylase, $\mathrm{Hy}$ perfine Interact. 141/142, 261 (2002).

[20] S.E. Enescu, I. Bibicu, V. Zoran, A. Kluger, A.D. Stoica, and V. Tripadus, A PC-based set-up for Rayleigh scattering of Mössbauer radiation, Measur. Sci. Technol. 9, 708 (1998).

[21] F.G. Parak, K. Achterhold, M. Schmidt, V. Prusakov, and S. Croci, Protein dynamics on different timescales, J. Non-Cryst. Solids 352, 4371 (2006).

[22] K.S. Singwi and A. Sjolander, Resonance absorbtion of nuclear gamma rays and the dynamics of atomic motion, Phys. Rev. 120, 1093 (1960).

[23] V.N. Gavrilov, E.V. Zolotojabko, and E.M. Iolin, Line broadening effect in the Rayleigh scattering of Mössbauer radiation on single crystals. Phys. Lett. A 75, 429 (1980).

[24] Yu.F. Krupyanskii, S.V. Esin, G.V. Eshenko, and M.G. Michailyuk, Spatio-temporal features of protein specific motions. The influence of hydration, J. Biol. Phys. 28, 139-145 (2002).

[25] Yu.F. Krupyanskii, S.V. Esin, G.V. Eshenko, and M.G. Michailyuk, Equilibrium fluctuations in lysozyme and myoglobin, Hyperfine Interact. 141-142, 273-277 (2002).

[26] S.K. Basovets, I.V. Uporov, K.V. Shaitan, Yu.F. Krupyanskii, I.V. Kurinov, I.P. Suzdalev, A.B. Rubin, and V.I. Goldanskii, A method of Mössbauer Fourier spectroscopy for determination of the biopolimer coordinate correlation functions, Hyperfine Interact. 39, 369 (1988).

[27] E.W. Knapp, S.F. Fischer, and F. Parak, Protein dynamics from Mössbauer spectra. The temperature dependance, J. Phys. Chem. 86, 5042 (1982).

[28] G.U. Nienhaus, F. Drepper, F. Parak, R.L. Mössbauer, D. Bade, and W. Hoppe, A multiwire proportional counter with spherical drift chamber for protein crystallography with X-rays and gamma-rays, Nucl. Instrum. Methods A 256, 581 (1987).

[29] G.U. Nienhaus and F. Parak, Rayleigh scattering of Mössbauer radiation on met-myoglobin, Hyperfine Interact. 29, 1451 (1986).

[30] C. Zach, C. Keppler, E. Huenges, K. Achterhold, and F. Parak, Angular- and temperature-dependent RSMR on myoglobin using ${ }^{183} \mathrm{~W}$ and ${ }^{57} \mathrm{Fe}$, Hyperfine Interact. 126, 83 (2000). 
[31] I.P. Suzdalev, Yu.F. Krupyanskii, and V.I. Goldanskii, Electronic state of the iron atom in heme and protein molecular motion studied by Mössbauer spectroscopy, J. Mol. Catal. 47, 179 (1988).
[32] Yi-Long Chen and De-Ping Yang, Mössbauer Effect in Lattice Dynamics: Experimental Techniques and Applications (Wiley-VCH, Weinheim, 2007).

\title{
PUSLAIDININKINIO DETEKTORIAUS PANAUDOJIMAS MESBAUERIO SPINDULIUOTĖS RELEJJAUS SKLAIDAI REGISTRUOTI
}

\author{
J. Reklaitis, D. Baltrūnas, V. Remeikis, K. Mažeika
}

Valstybinis moksliniu tyrimu institutas Fiziniu ir technologijos mokslu centras, Vilnius, Lietuva

\section{Santrauka}

Mesbauerio spinduliuotès Relèjaus sklaidos metodas pritaikytas atomų dinamikos polistirene tyrimui, išsklaidytos spinduliuotès registracijai, pasirenkant puslaidininkini Si-PIN detektorių. Puslaidininkinis detektorius, palyginus su dažniausiai naudojamu proporcingu detektoriumi, pasižymi daug geresne energine skiriamaja geba ir juo galima gauti geresnès kokybès Mesbauerio spinduliuotès Relejjaus sklaidos spektrus esant toms pačioms kolimavimo sąlygoms.
Gauta Relèjaus elastinès sklaidos polistirene tikimybės $f_{\mathrm{R}}$ priklausomybè nuo sklaidos kampo. Mesbauerio spinduliuotės Relejaus sklaidos metodas taikytas esant sklaidos kampams intensyvumo maksimume, kuris atitinka vidutini tarpplokštumini atstumą $d=4,44 \AA$ ir gali būti siejamas su atstumu tarp polimero grandinių polistirene. 